\title{
Closed Uranyl-Dicarboxylate Oligomers: a Tetranuclear Metallatricycle with Uranyl Bridgeheads and 1,3-Adamantanediacetate Linkers
}

\author{
Pierre Thuéry, ${ }^{* \dagger} \dagger$ Youssef Atoini ${ }^{\ddagger}$ and Jack Harrowfield $*, *$ \\ †NIMBE, CEA, CNRS, Université Paris-Saclay, CEA Saclay, 91191 Gif-sur-Yvette, France \\ ¥ISIS, Université de Strasbourg, 8 allée Gaspard Monge, 67083 Strasbourg, France
}

\section{Supporting Information Placeholder}

\begin{abstract}
In the presence of $\mathrm{NH}_{4}{ }^{+}$and either $\mathrm{PPh}_{4}{ }^{+}$or $\mathrm{PPh}_{3} \mathrm{Me}^{+}$cations, 1,3-adamantanediacetic acid (H $\mathrm{ADA}$ ) reacts with uranyl ions under solvo-hydrothermal conditions to give the complexes $\left[\mathrm{NH}_{4}\right]_{2}\left[\mathrm{PPh}_{4}\right]_{2}\left[\left(\mathrm{UO}_{2}\right)_{4}(\mathrm{ADA})_{6}\right](\mathbf{1})$ and $\left[\mathrm{NH}_{4}\right]_{2}\left[\mathrm{PPh}_{3} \mathrm{Me}\right]_{2}\left[\left(\mathrm{UO}_{2}\right)_{4}(\mathrm{ADA})_{6}\right](2)$, both of which contain a tetranuclear metallatricycle built from two $2: 2$ rings including convergent ligands, linked by two additional ligands in extended conformation defining a third, larger ring. While the ammonium cations are closely associated with the 2:2 rings through triple hydrogen bonding, the large $\mathrm{PPh}_{4}^{+}$or $\mathrm{PPh}_{3} \mathrm{Me}^{+}$ cations are more loosely bound to each of the two faces of the larger ring. In contrast, the complex $\left[\mathrm{H}_{2} \mathrm{NMe}_{2}\right]\left[\mathrm{PPh}_{3} \mathrm{Me}\right]\left[\left(\mathrm{UO}_{2}\right)_{2}(\mathrm{ADA})_{3}\right] \cdot \mathrm{H}_{2} \mathrm{O}(3)$, in which dimethylammonium replaces ammonium cations, crystallizes as a twodimensional network with honeycomb $\left\{6^{3}\right\}$ topology, albeit with very distorted, elongated hexagonal cells. These and previous results show that both $\mathrm{NH}_{4}{ }^{+}$and $\mathrm{PPh}_{4}{ }^{+}$or $\mathrm{PPh}_{3} \mathrm{Me}^{+}$cations are essential to the formation of the metallatricycle. The role of the flexibility imparted to $\mathrm{ADA}^{2-}$ by the acetate arms, when compared to the more rigid 1,3-adamantanedicarboxylate (ADC ${ }^{2-}$ ), is also discussed. All three complexes are luminescent, with quantum yields of 0.06, 0.06, and 0.09 for 1, 2, and 3, respectively. The vibronic fine structure apparent on the emission spectra gives maxima positions typical of species in which the uranyl ion is chelated by three carboxylate groups.
\end{abstract}

\section{INTRODUCTION}

In contrast to the present development of studies of uranylorganic polymeric structures, ${ }^{1-4}$ those of uranyl-based closed species, such as rings, ${ }^{5-7}$ cages, ${ }^{7-13}$ nanospheres ${ }^{14-19}$ and nanotubes, ${ }^{10,20-30}$ are much more fragmentary, apart from the family of peroxo-bridged clusters, which has been very thoroughly investigated. ${ }^{15-19}$ The syntheses, structures and potential applications of such closed species, in particular those involving carboxylate ligands, have recently been reviewed. ${ }^{4}$ Although a common pattern in uranyl carboxylate structures is that of honeycomb networks involving fused metallacyclic species, examples of isolated rings, or more properly metallacycles, in particular, are very rare, being limited to tri- and tetranuclear species with 2,3,4,5-tetrahydrofurantetracarboxylate, ${ }^{5}$ hexanuclear ones with benzoate ${ }^{6}$ and iminodiacetate ${ }^{26}$ (the latter organized into nanotubular arrays), and a heterometallic uranylcopper(II) dodecanuclear complex with Kemp's tricarboxylate. ${ }^{7}$ Apart from the choice of a ligand geometrically suitable to form a closed species ${ }^{31}$ (notwithstanding that many such species are of a fairly unexpected nature), conditions promoting their formation need to be more closely investigated. Of particular interest is the exploration of factors, among which one expected to be of significance is that of ligand flexibility, ${ }^{32-34}$ leading to the extension of closed monocyclic structures into three- dimensional cages, such uranyl species, ${ }^{7-13}$ again as yet rare, having potential applications as selective photocatalysts.

Recently, we have described a pseudo-cubic octanuclear uranyl cage complex with cis-1,2-cyclohexanedicarboxylate ligands obtained through use of $\mathrm{PPh}_{4}{ }^{+}$and $\mathrm{NH}_{4}{ }^{+}$counterions (the latter generated in situ) under solvo-hydrothermal conditions. ${ }^{35}$ While an ammonium cation, held within the cage by hydrogen bonding, probably exerts a structuredirecting effect, it may be surmised that the $\mathrm{PPh}_{4}{ }^{+}$cations are efficient as bulky separators preventing polymerization. In order to put this possibility to the test, we attempted similar syntheses using different polycarboxylic acids potentially able to form bridges with a geometry suitable to generate closed species. One of them, 1,3-adamantanediacetic acid $\left(\mathrm{H}_{2} \mathrm{ADA}\right)$, previously known to form various one- and twodimensional polymers based on fused cyclic structures with uranyl ions, ${ }^{36,37}$ proved to respond appropriately to these conditions in generating a tetranuclear uranyl cage. The synthesis, crystal structure and luminescence properties of three uranyl complexes obtained during this work are reported herein.

\section{EXPERIMENTAL SECTION}

Synthesis. Caution! ${ }^{238} U$ is a radioactive element, and its complexes must be handled with suitable care and protection. 
$\mathrm{UO}_{2}\left(\mathrm{NO}_{3}\right)_{2} \cdot 6 \mathrm{H}_{2} \mathrm{O}$ (depleted uranium, R. P. Normapur, 99\%) was purchased from Prolabo, and 1,3adamantanediacetic acid $\left(\mathrm{H}_{2} \mathrm{ADA}\right)$ from Aldrich. Elemental analyses were performed by MEDAC Ltd. at Chobham, UK.

$\left[\mathrm{NH}_{4}\right]_{2}\left[\mathrm{PPh}_{4}\right]_{2}\left[\left(\mathrm{UO}_{2}\right)_{4}(\mathrm{ADA})_{6}\right]$ (1) and $\left[\mathrm{NH}_{4}\right]_{2}\left[\mathrm{PPh}_{3} \mathrm{Me}_{2^{-}}\right.$ $\left[\left(\cup_{2}\right)_{4}(A D A)_{6}\right]$ (2) (values for the latter in brackets): $\mathrm{H}_{2} \mathrm{ADA}$ (25 mg, $0.10 \mathrm{mmol}), \mathrm{UO}_{2}\left(\mathrm{NO}_{3}\right)_{2} \cdot 6 \mathrm{H}_{2} \mathrm{O}(35 \mathrm{mg}, 0.07 \mathrm{mmol})$, and $\mathrm{PPh}_{4} \mathrm{Br}$ (42 mg, $\left.0.10 \mathrm{mmol}\right)\left[\mathrm{PPh}_{3} \mathrm{MeBr}(36 \mathrm{mg}, 0.10\right.$ $\mathrm{mmol})]$ were dissolved in a mixture of water $(0.6 \mathrm{~mL})$, acetonitrile $(0.2 \mathrm{~mL})$, and DMF $(0.2 \mathrm{~mL})$, and heated at 140 ${ }^{\circ} \mathrm{C}$ under autogenous pressure, giving light yellow crystals of complex 1 [2] within 3 days (38 [26] mg, 69\% [49\%] yield based on the acid). Anal. Calcd for $1, \mathrm{C}_{132} \mathrm{H}_{156} \mathrm{~N}_{2} \mathrm{O}_{32} \mathrm{P}_{2} \mathrm{U}_{4}$ : C, 48.09; H, 4.77; N, 0.85. Found: C, 47.96; H, 4.73; N, 1.56\% [Anal. Calcd for 2, $\mathrm{C}_{122} \mathrm{H}_{152} \mathrm{~N}_{2} \mathrm{O}_{32} \mathrm{P}_{2} \mathrm{U}_{4}$ : C, 46.19; H, 4.83; N, 0.88. Found: $\mathrm{C}, 45.49 ; \mathrm{H}, 4.75 ; \mathrm{N}, 1.95 \%]$.

$\left[\mathrm{H}_{2} \mathrm{NMe}_{2}\right]\left[\mathrm{PPh}_{3} \mathrm{Me}\right]\left[\left(\mathrm{UO}_{2}\right)_{2}(\mathrm{ADA})_{3}\right] \cdot \mathrm{H}_{2} \mathrm{O} \quad$ (3): $\quad$ synthesis analogous to that of $\mathbf{2}$, but for the absence of acetonitrile. Yellow crystals of $\mathbf{3}$ were obtained within 3 days (48 mg, $88 \%$ yield based on the acid). Anal. Calcd for $\mathbf{3}$, $\mathrm{C}_{63} \mathrm{H}_{82} \mathrm{NO}_{17} \mathrm{PU}_{2}$ : C, 46.36; $\mathrm{H}, 5.06 ; \mathrm{N}, 0.86$. Found: $\mathrm{C}$, 46.30; H, 5.00; N, $1.45 \%$.

Crystallography. Crystallographic data were collected at $150(2) \mathrm{K}$ (1 and 2) or 100(2) K (3) on a Nonius KappaCCD area-detector diffractometer using graphitemonochromated Mo K $\alpha$ radiation $(\lambda=0.71073 \AA) .{ }^{38}$ The crystals were introduced into glass capillaries with a protecting Paratone-N oil (Hampton Research) coating. The unit cell parameters were determined from ten frames, then refined on all data. The data (combinations of $\varphi$ - and $\omega$-scans with a minimum redundancy of 4 for $90 \%$ of the reflections) were processed with HKL2000. ${ }^{39}$ Absorption effects were corrected empirically with the program SCALEPACK. ${ }^{39}$ The structures were solved by intrinsic phasing with SHELXT, ${ }^{40}$ and refined by full-matrix least-squares on $F^{2}$ with SHELXL-2014. ${ }^{41}$ All non-hydrogen atoms were refined with anisotropic displacement parameters. The hydrogen atoms of the ammonium cations were retrieved from difference Fourier maps in $\mathbf{1}$ and $\mathbf{2}$, while those in $\mathbf{3}$ and the carbon-bound hydrogen atoms in all compounds were introduced at calculated positions; the hydrogen atoms of the water molecule in $\mathbf{3}$ were not found; all hydrogen atoms were treated as riding atoms with an isotropic displacement parameter equal to 1.2 times that of the parent atom (1.5 for $\mathrm{CH}_{3}$, with optimized geometry). In $\mathbf{1}$ and $\mathbf{2}$, large voids in the lattice indicate the presence of solvent molecules (probably water and possibly also acetonitrile) which could not be resolved, and SQUEEZE (PLATON) ${ }^{42}$ was used to take into account the contribution of these disordered solvent molecules. As indicated by elemental analysis results, this solvent is largely lost when the crystals are dried using a water aspirator. The drawings were made with ORTEP-3/POV-Ray ${ }^{43}$ and VESTA. ${ }^{44}$

Crystal data for 1: $\mathrm{C}_{132} \mathrm{H}_{156} \mathrm{~N}_{2} \mathrm{O}_{32} \mathrm{P}_{2} \mathrm{U}_{4}, \quad M=3296.64$, monoclinic, space group $C 2 / c, a=28.8294(9), b=$ $30.9496(11), c=15.7427(8) \AA, \beta=110.542(4)^{\circ}, V=$ 13153.4(10) $\AA^{3}, Z=4$. Refinement of 775 parameters on 12471 independent reflections out of 215619 measured reflections $\left(R_{\text {int }}=0.050\right)$ led to $\mathrm{R} 1=0.031$, wR2 $=0.068, S$ $=1.087, \Delta \rho_{\min }=-0.89, \Delta \rho_{\max }=0.50 \mathrm{e}^{-3}$.

Crystal data for 2: $\mathrm{C}_{122} \mathrm{H}_{152} \mathrm{~N}_{2} \mathrm{O}_{32} \mathrm{P}_{2} \mathrm{U}_{4}, M=3172.51$, monoclinic, space group $P 2{ }_{1} / c, a=14.7546(6), b=$ 28.1736(9), $c=15.9461(6) \AA, \quad \beta=99.770(2)^{\circ}, \quad V=$ $6532.5(4) \AA^{3}, Z=2$. Refinement of 731 parameters on 12373 independent reflections out of 145115 measured reflections $\left(R_{\text {int }}=0.073\right)$ led to $\mathrm{R} 1=0.043, \mathrm{wR} 2=0.114, S=$ $0.947, \Delta \rho_{\min }=-0.97, \Delta \rho_{\max }=1.49 \mathrm{e} \AA^{-3}$.

Crystal data for 3: $\mathrm{C}_{63} \mathrm{H}_{82} \mathrm{NO}_{17} \mathrm{PU}_{2}, \quad M=1632.32$, monoclinic, space group $P 2{ }_{1} / c, a=15.9997(4), b=$ 22.9290(5), $c=16.7751(4) \AA, \quad \beta=95.1369(14)^{\circ}, V=$ 6129.4(3) $\AA^{3}, Z=4$. Refinement of 760 parameters on 11626 independent reflections out of 218632 measured reflections $\left(R_{\text {int }}=0.031\right)$ led to $\mathrm{R} 1=0.026, \mathrm{wR}_{2}=0.062, S=$ $1.027, \Delta \rho_{\min }=-0.90, \Delta \rho_{\max }=1.43 \mathrm{e}^{-3}$.

Luminescence measurements. Steady-state emission spectra were recorded on a Horiba Jobin-Yvon IBH FL-322 Fluorolog 3 spectrometer equipped with a $450 \mathrm{~W}$ xenon arc lamp, double-grating excitation and emission monochromator $\left(2.1 \mathrm{~nm} \mathrm{~mm}^{-1}\right.$ of dispersion; 1200 grooves $\mathrm{mm}^{-1}$ ), and a TBX-04 single photon-counting detector. Emission and excitation spectra were corrected for source intensity (lamp and grating) and emission spectral response (detector and grating) by standard correction curves. The quantum yield measurements were performed by using an absolute photoluminescence quantum yield spectrometer Hamamatsu Quantaurus C11347, exciting the sample between 300 and $400 \mathrm{~nm}$.

\section{RESULTS AND DISCUSSION}

Synthesis. The possible role of a cosolvent as a chemical reagent in solvothermal syntheses is once more nicely illustrated in the present system. It is clear that both acetonitrile and dimethylformamide undergo hydrolysis (possibly catalysed by uranyl ion) under the reaction conditions, as previously observed, ${ }^{13,35}$ here providing cations which can both be incorporated into distinct crystalline solids, although with a solubility difference favouring ammonium over dimethylammonium. The presence of large phosphonium cations appears to be essential for the formation of a lattice incorporating the closed metallatricycle, their mulitple weak interactions resulting, along with hydrogen bonding to the ammonium ion (see below), in the effective isolation of the tricycle and prevention of a higher degree of uranyl/carboxylate oligomerization.

Crystal Structures. The two complexes $\left[\mathrm{NH}_{4}\right]_{2}\left[\mathrm{PPh}_{4}\right]_{2}\left[\left(\mathrm{UO}_{2}\right)_{4}(\mathrm{ADA})_{6}\right] \quad$ (1) and $\left[\mathrm{NH}_{4}\right]_{2}\left[\mathrm{PPh}_{3} \mathrm{Me}\right]_{2}\left[\left(\mathrm{UO}_{2}\right)_{4}(\mathrm{ADA})_{6}\right]$ (2) were synthesized in the presence of either $\mathrm{PPh}_{4} \mathrm{Br}$ or $\mathrm{PPh}_{3} \mathrm{MeBr}$, and $\mathrm{NH}_{4}{ }^{+}$ cations, and their crystal structures were determined. Although not isomorphous, these two compounds contain the same centrosymmetric $\left[\left(\mathrm{UO}_{2}\right)_{4}(\mathrm{ADA})_{6}\right]^{4-}$ tetranuclear anion (Figures 1, 2 and S1, Supporting Information). The two crystallographically independent uranyl cations are 

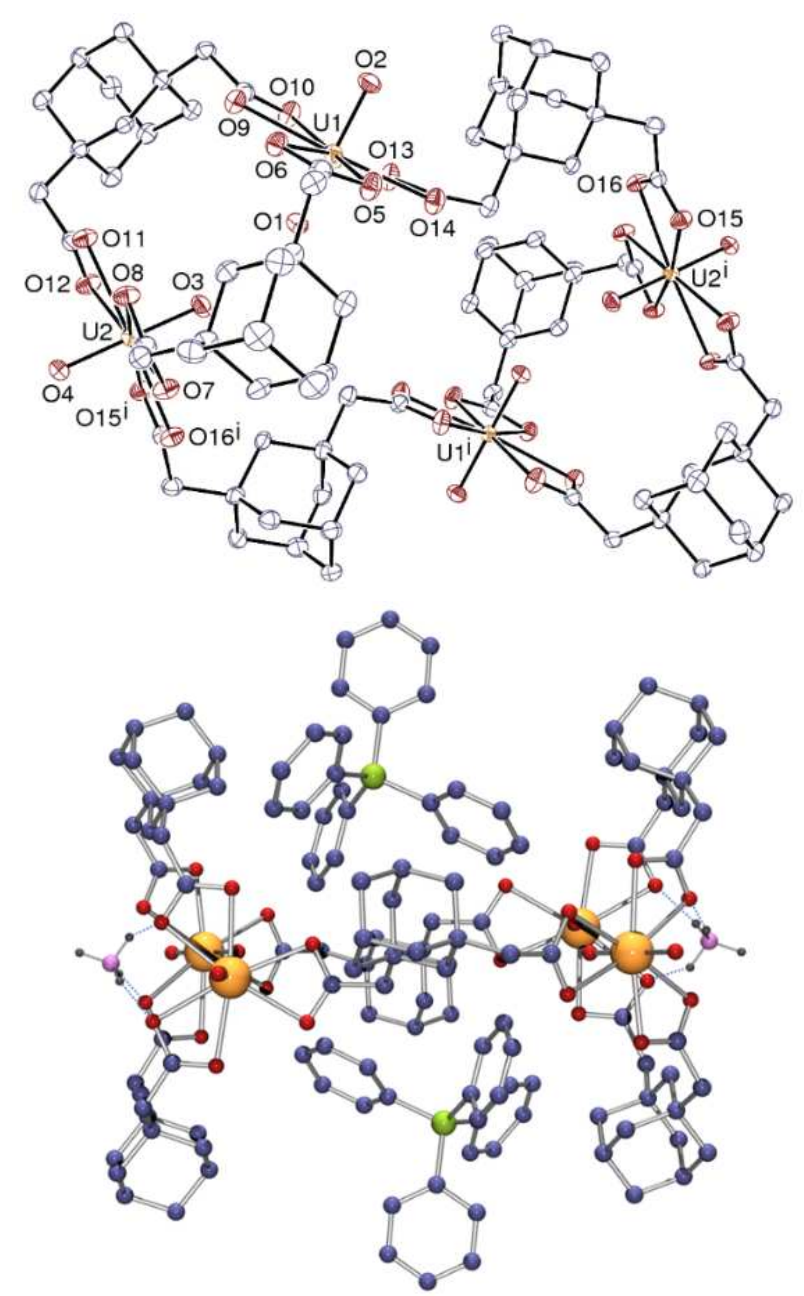

Figure 1. Top: View of the tetranuclear complex in 1. Displacement ellipsoids are drawn at the $40 \%$ probability level and hydrogen atoms are omitted. Symmetry code: $\mathrm{i}=3 / 2-x, 1 / 2-y, 1-z$. Bottom: View showing the arrangement of $\mathrm{PPh}_{4}{ }^{+}$and $\mathrm{NH}_{4}{ }^{+}$cations around the tetranuclear complex. Hydrogen bonds are shown as dashed lines.

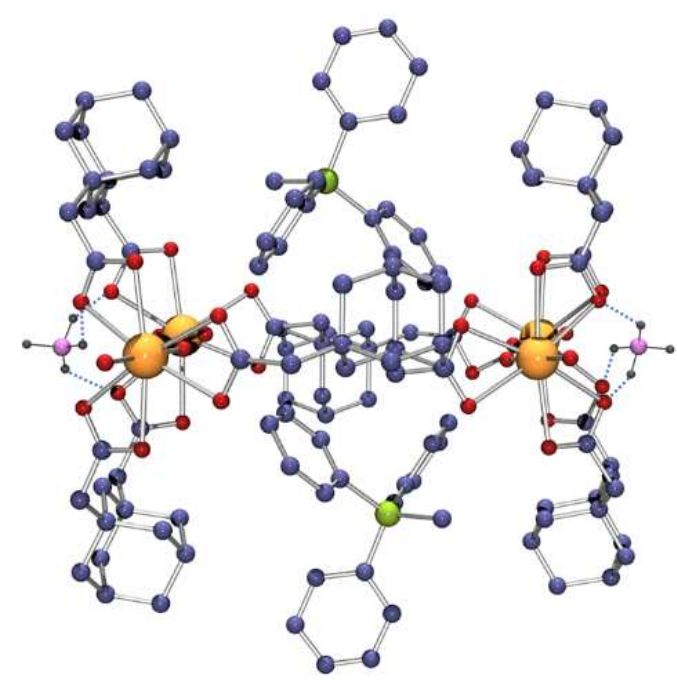

Figure 2. View showing the arrangement of $\mathrm{MePPh}_{3}{ }^{+}$and $\mathrm{NH}_{4}{ }^{+}$cations around the tetranuclear complex in $\mathbf{2}$. Hydrogen bonds are shown as dashed lines. chelated by three carboxylate groups from three ligands [U$\mathrm{O}$ (oxo) bond lengths 1.757(3)-1.787(5) §, UO(carboxylate) 2.430(5)-2.519(5) $\AA$, including both compounds]. Two of the ligands assume a conformation with convergent donor sites, the two carboxylate groups pointing toward the same side, with dihedral angles of 45.1(5) and $42.4(4)^{\circ}$ in 1 , and 62.2(7) and 57.5(8) in 2. These two ligands and atoms U1 and U2 form a 20membered dinuclear metallacycle in which the uranyl equatorial planes are strongly tilted with respect to the average ring plane, the distance between the oxo groups directed inwards being 3.026(4) $\AA$ in 1 and 3.596(7) $\AA$ in 2. The shape of the third ligand in $\mathbf{1}$ and $\mathbf{2}$ is different from that of the other two, with one of the carboxylate groups rotated so as to be directed sideways, the two coordination sites being thus divergent. Two of these ligands bridge two dinuclear 20-membered metallacycle units to form a tetranuclear complex involving an additional 40-membered ring. The four uranium ions define a parallelogram with side lengths of 6.1851(3) and 11.1265(4) $\AA$ in $\mathbf{1}$ and 6.7346(4) and $11.0807(5) \AA$ in 2 . The $\mathrm{U} 2 \cdots \mathrm{U} 1 \cdots \mathrm{U} 2^{\mathrm{i}}$ angles are $109.393(3)$ and $115.464(4)^{\circ}$, and the $\mathrm{U} 1 \cdots \mathrm{U} 2 \cdots \mathrm{U} 1^{\mathrm{i}}$ angles are $70.607(3)$ and $64.536(4)^{\circ}$ in $\mathbf{1}$ and $\mathbf{2}$, respectively. Although the overall geometry is the same in both complexes, these differences in distances and angles show that the system is sufficiently flexible to allow for some counterion-induced variations. The 20-membered metallacycle is very similar to that found in the onedimensional (1D) polymeric chains in the lattice of $\left[\mathrm{UO}_{2}(\mathrm{ADA})\left(\mathrm{H}_{2} \mathrm{O}\right)\right]$, but that in $\left[\mathrm{UO}_{2}(\mathrm{ADA})(\mathrm{NMP})\right](\mathrm{NMP}=$ $\mathrm{N}$-methyl-2-pyrrolidone), with otherwise similar 1D chains, is more elongated due to the divergent orientation of the carboxylate groups, ${ }^{36}$ as is also the case for the similar chain found in $\left[\left(\mathrm{UO}_{2}\right)_{2}(\mathrm{ADA})_{2}\left(\mathrm{HCO}_{2} \mathrm{H}\right)_{2}\right] \cdot \mathrm{CB} 6 \cdot 6 \mathrm{H}_{2} \mathrm{O} \quad(\mathrm{CB} 6=$ cucurbit[6]uril). ${ }^{37}$ With respect to 1,3 adamantanedicarboxylate $\left(\mathrm{ADC}^{2-}\right),{ }^{37,45,46}$ the insertion of a $\mathrm{C}-\mathrm{C}$ bond between the adamantyl and carboxylate units allows a degree of conformational freedom which is reflected in the different conformations observed in these complexes. Significantly, the ring found in $\left[\mathrm{UO}_{2}(\mathrm{ADA})\left(\mathrm{H}_{2} \mathrm{O}\right)\right]$ is reinforced by reciprocal intra-ring hydrogen bonding of coordinated water and uranyl oxo units, resulting in a $\mathrm{U} \cdots \mathrm{U}$ separation across the ring of 5.3016(4) $\AA$, smaller than in $\mathbf{1}$ and 2 , compared to $10.8228(5) \AA$ in the ring of $\left[\mathrm{UO}_{2}(\mathrm{ADA})(\mathrm{NMP})\right]$ and $10.7598(5) \AA$ in that of $\left[\left(\mathrm{UO}_{2}\right)_{2}(\mathrm{ADA})_{2}\left(\mathrm{HCO}_{2} \mathrm{H}\right)_{2}\right]$. CB6 $6 \mathrm{H}_{2} \mathrm{O}$. The tetra-anionic cluster in $\mathbf{1}$ and $\mathbf{2}$ thus appears to be built from two $\left(\mathrm{UO}_{2}\right)_{2}(\mathrm{ADA})_{2}$ neutral rings linked by two more $\mathrm{ADA}^{2-}$ anions making a third, central ring (although one which has two possible terminations on either side). When viewed with the $\mathrm{U}_{4}$ plane edge-on, the anion displays a dumbbell shape, the smallest rings defining a cleft on each side. In its uranyl ion complexes, the $\mathrm{ADA}^{2-}$ anion is known to display a preference for divergent ligation, and this is largely true in its metal ion complexes more generally, as appears from the structures reported in the Cambridge Structural Database (Version 5.38), ${ }^{47}$ but cases of convergent bridging leading to formation of $2: 2$ metallacyclic subunits in addition to that of $\left[\mathrm{UO}_{2}(\mathrm{ADA})\left(\mathrm{H}_{2} \mathrm{O}\right)\right]$ noted above are known, for example in cobalt(II), zinc(II) or cadmium(II) chemistry. ${ }^{48-50}$ 
Metallacycles can also be generated with a more divergent form of this ligand. ${ }^{51}$

The convergent form of $\mathrm{ADA}^{2-}$ found in the 20membered metallacycles of $\mathbf{1}$ and $\mathbf{2}$ is associated with multiple hydrogen bonding interactions involving the ammonium cations, reflected again in the relatively short intra-annular $\mathrm{U} \cdots \mathrm{U}$ separations. The ammonium ions are held above the centre of each dinuclear ring by three hydrogen bonds with carboxylate groups [N $\cdots \mathrm{O}$ distances

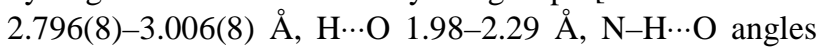
$\left.119-169^{\circ}\right]$, and they make a fourth hydrogen bond with a carboxylate group of a neighbouring unit, so that hydrogen bonded two-dimensional (2D) networks parallel to $\left(\begin{array}{lll}1 & 0 & 0\end{array}\right)$ are formed (Figures 3 and 4). These sheets assume slightly different shapes in $\mathbf{1}$ and $\mathbf{2}$, the views down the $c$ axis showing more pronounced corrugation in the latter. In both, some of the adamantyl groups and aromatic rings are pointing outwards.
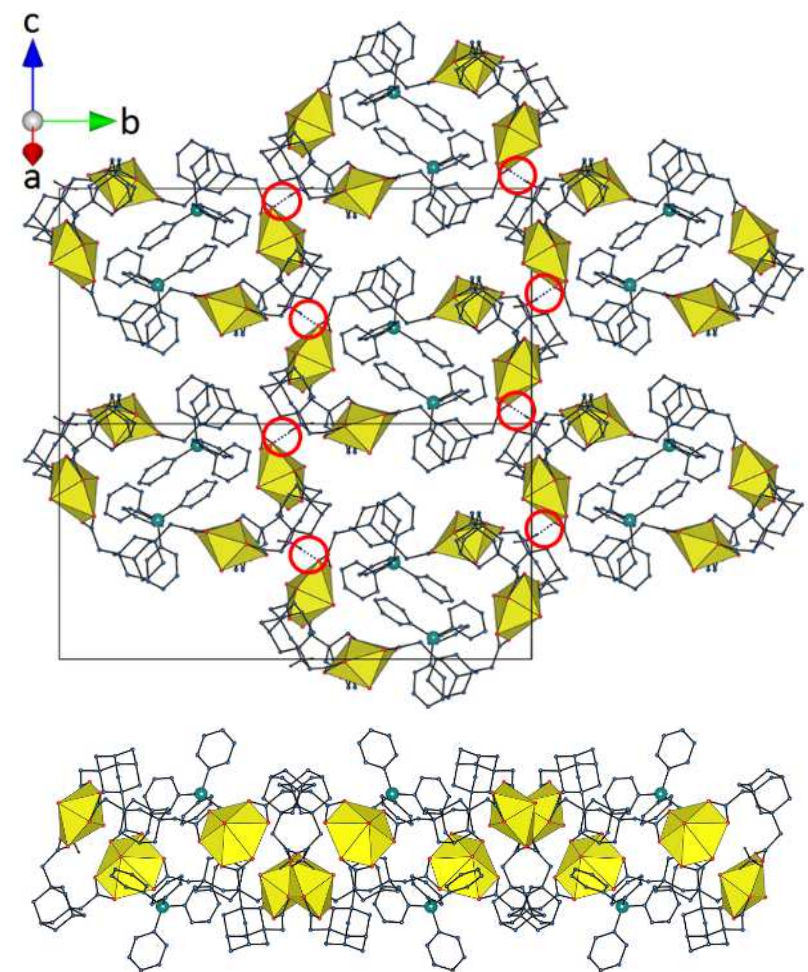

Figure 3. Two views of the hydrogen bonded 2D assembly in $\mathbf{1}$ with uranium coordination polyhedra colored yellow and carbon-bound hydrogen atoms omitted. Hydrogen bonds linking adjacent clusters are indicated by red circles on the top view. The lower view is down the $c$ axis.

The $\mathrm{PPh}_{4}^{+}$or $\mathrm{PPh}_{3} \mathrm{Me}^{+}$counterions are located within the clefts on both sides of the complex, with either three aromatic rings or two rings and the methyl group pointing inwards (Figures 1 and 2). Besides electrostatic interactions, the counterions in $\mathbf{1}$ may be involved in two weak $\mathrm{CH} \cdots \pi$ interactions involving protons from the adamantyl groups $[\mathrm{H} \cdots$ centroid 2.86 and $2.94 \AA, \mathrm{C}-\mathrm{H} \cdots$ centroid 140 and $\left.151^{\circ}\right]$, and the aromatic ring pointing outwards may form a $\pi$-stacking interaction with its counterpart in the neighbouring layer [centroid $\cdots$ centroid $4.582(3) \AA$, dihedral angle $50^{\circ}$ ]. In both 1 and 2 , some $\mathrm{CH}$ (aromatic/methyl) $\cdots$
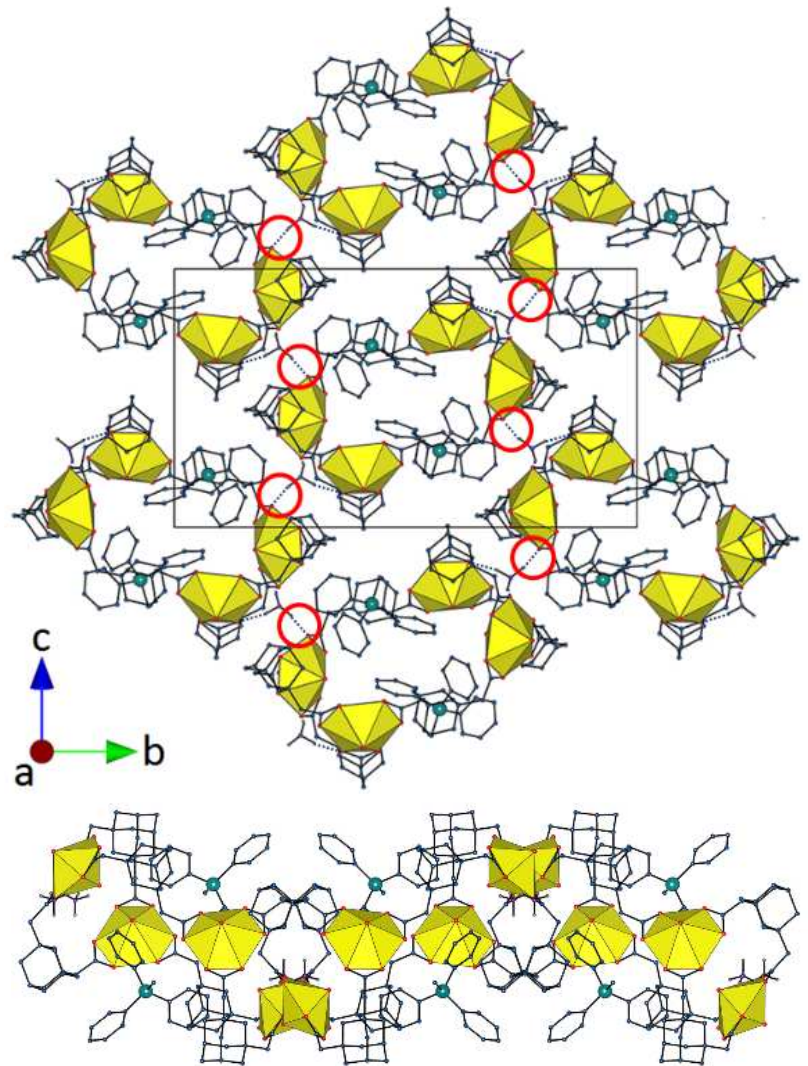

Figure 4. Two views of the hydrogen bonded 2D assembly in 2 with uranium coordination polyhedra colored yellow and carbon-bound hydrogen atoms omitted. Hydrogen bonds linking adjacent clusters are indicated by red circles on the top view. The lower view is down the $c$ axis.

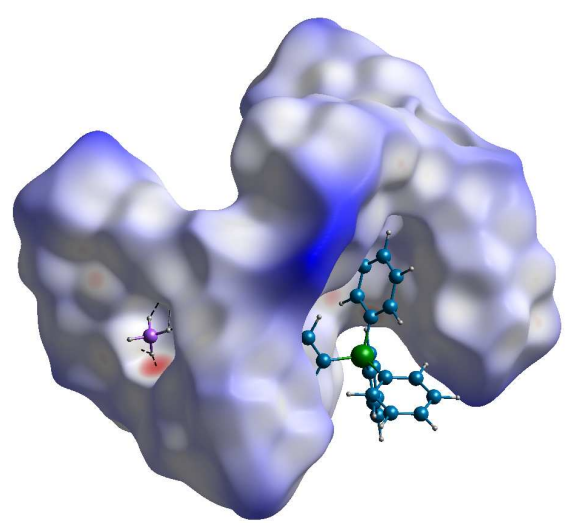

Figure 5. Hirshfeld surface of the anionic cluster in 1 mapped with $d_{\text {norm }}$. Hydrogen bonds with the ammonium cation are shown as dashed lines.

$\mathrm{O}$ (carboxylate) hydrogen bonds ${ }^{52-54}$ are possibly present $[\mathrm{C} \cdots \mathrm{O} 3.064(6)-3.260(5) \AA]$. The last are the only ones among these weak interactions to appear clearly on the Hirshfeld surfaces ${ }^{55}$ calculated with CrystalExplorer ${ }^{56}$ (Figures 5 and S2), the other interactions being no stronger than dispersion. Although $\mathrm{PPh}_{4}{ }^{+}$and $\mathrm{PPh}_{3} \mathrm{Me}^{+}$cations are known to readily assemble with one another through "phenyl embraces' 57 a close phosphonium pair is only observed in 1, where, aside from dispersion, there appears to be only a single, reciprocal $\mathrm{CH} \cdots \mathrm{C}$ interaction between cations with a P...P separation of 7.019(2) A. This interaction may in part explain the lesser penetration of the phosphonium cations into the clefts in $\mathbf{1}$ when compared to $\mathbf{2}$, reflected in P...P 
separations across the large ring of 10.345(2) and 9.418(5) $\AA$, respectively.

It thus appears that counterions are associated with each ring of the complex: one ammonium cation with each of the $\left(\mathrm{UO}_{2}\right)_{2}(\mathrm{ADA})_{2}$ lateral rings, and two $\mathrm{PPh}_{4}{ }^{+}$or $\mathrm{PPh}_{3} \mathrm{Me}^{+}$ cations with the clefts supported by the central ring, thus generating a globular neutral moiety. This is indicative of the structure-directing role possibly played by these cations. It is notable that $\mathrm{NH}_{4}{ }^{+}$cations have also been found to be held through multiple hydrogen bonding within uranylcontaining nanotubules formed with tricarballylate ligands, ${ }^{30}$ and octanuclear cages with cis-1,2cyclohexanedicarboxylate. ${ }^{35}$ Its small size and high assembling power through directional hydrogen bonding make this cation an ideal structure-directing agent in cases in which, as here and in the species cited above, a close arrangement of acceptor carboxylate groups is desired. In contrast, the large $\mathrm{PPh}_{4}{ }^{+}$or $\mathrm{PPh}_{3} \mathrm{Me}^{+}$cations interact with the anion essentially through weaker $\mathrm{CH}$... O hydrogen bonds, apart from coulombic interactions, and their effects are probably predominantly due to their size and shape, the most efficient packing being that associating cation and cleft.

The essential role played by the $\mathrm{NH}_{4}{ }^{+}$cations in the formation of the molecular cluster in $\mathbf{1}$ and $\mathbf{2}$ is further confirmed by the crystal structure of the complex $\left[\mathrm{H}_{2} \mathrm{NMe}_{2}\right]\left[\mathrm{PPh}_{3} \mathrm{Me}\right]\left[\left(\mathrm{UO}_{2}\right)_{2}(\mathrm{ADA})_{3}\right] \cdot \mathrm{H}_{2} \mathrm{O}(3)$. This complex was obtained in conditions similar to those for $\mathbf{2}$, but for the absence of acetonitrile and the resulting $\mathrm{NH}_{4}{ }^{+}$cations, dimethylammonium cations due to DMF hydrolysis, a very common occurrence, ${ }^{13,58,59}$ being present instead. The asymmetric unit in $\mathbf{3}$ contains two uranyl cations, both chelated by three carboxylate groups pertaining to three $\mathrm{ADA}^{2-}$ ligands [U-O(oxo) bond lengths 1.768(3)-1.779(2) $\AA$, U-O(carboxylate) 2.414(2)-2.506(2) $\AA$ ], and three dicarboxylate ligands, two of which can be regarded as providing convergent donor atom arrays, while the third is clearly divergent (Figure 6). This connectivity results in the formation of a 2D coordination polymer parallel to $\left(\begin{array}{lll}0 & 0 & 1\end{array}\right)$, which has the point (Schläfli) symbol $\left\{6^{3}\right\}$ and the honeycomb (hcb) topological type, however very distorted. The 60-membered metallacyclic rings are very elongated, with a length of $\sim 25 \AA$, and the adamantyl groups pointing inwards leave virtually no free space. The layers are undulating and the $\mathrm{PPh}_{3} \mathrm{Me}^{+}$cations are located in the interlayer spaces (Figure S3). The $\mathrm{H}_{2} \mathrm{NMe}_{2}{ }^{+}$cation is hydrogen bonded to one carboxylate oxygen atom and to a water molecule (the latter possibly making a link with the neighbouring layer), so that it does not appear to have a role in bringing ligand units into close proximity. Although the $\mathrm{PPh}_{3} \mathrm{Me}^{+}$cations lie in pairs with a P...P distance of 9.076(2) $\AA$, they do not appear to be involved in mutual interactions beyond dispersion and are principally involved in $\mathrm{CH} \cdots \mathrm{O}$ interactions with the polymer, involving either the methyl or the aromatic groups as donors and carboxylate groups as acceptors, with C...O distances in the range of 3.267(4)$3.416(6) \AA$. Three hydrogen atoms of the $\mathrm{ADA}^{2-}$ ligands are also possibly involved in $\mathrm{CH} \cdots \pi$ interactions $(\mathrm{H} \cdots$ centroid 2.67-3.00 А). The structure of 3 thus shows that $\mathrm{PPh}_{3} \mathrm{Me}^{+}$ cations alone are not sufficient to promote the formation of the tetranuclear species, and that $\mathrm{NH}_{4}{ }^{+}$cations play an essential role, a further indication of the importance and subtle nature of hydrogen bonding in interaction with ligand flexibility in this family of compounds.
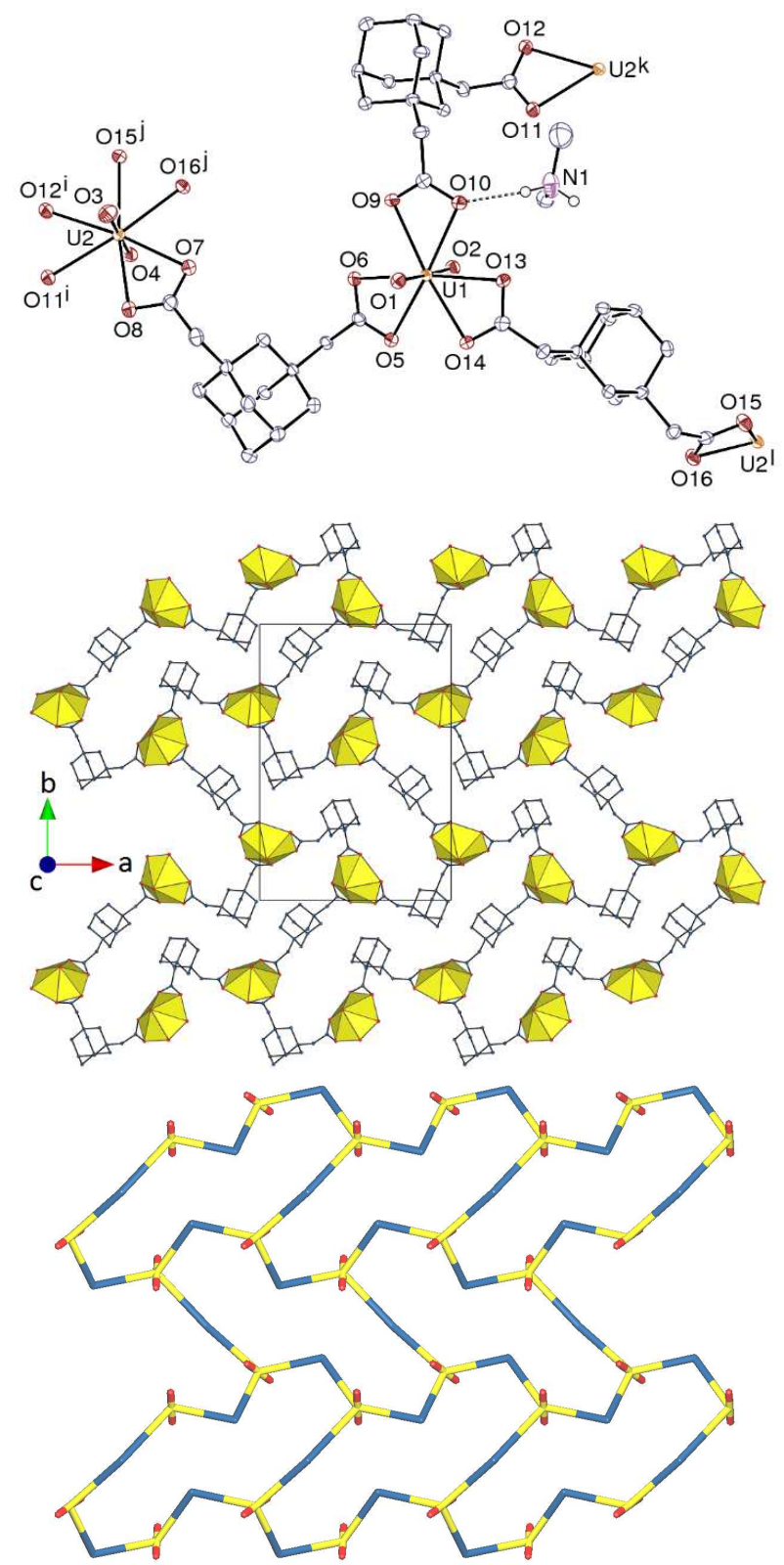

Figure 6. Top: View of complex 3. Displacement ellipsoids are drawn at the $50 \%$ probability level. $\mathrm{PPh}_{3} \mathrm{Me}^{+}$cations, solvent molecules and carbonbound hydrogen atoms are omitted. The hydrogen bond is shown as a dashed line. Symmetry codes: $\mathrm{i}=x+1, y, z ; \mathrm{j}=1-x, y+1 / 2,1 / 2-z ; \mathrm{k}=$ $x-1, y, z ; 1=1-x, y-1 / 2,1 / 2-z$. Middle: View of the $2 \mathrm{D}$ network. Bottom: Nodal representation of the network (yellow: uranium, red: oxygen, blue: dicarboxylate ligand).

Considering the general context of the structures of complexes 1 and 2, it must be noted that neither $\mathrm{PPh}_{4}{ }^{+}$nor $\mathrm{PPh}_{3} \mathrm{Me}^{+}$give coordination cages of uranyl ion with cyclohexanedicarboxylates when they are the only additional cations present, ${ }^{60}$ and that their association with $\mathrm{NH}_{4}{ }^{+}$again appears to be necessary to generate cages in their presence, as in the case of cis-1,2cyclohexanedicarboxylate. ${ }^{35}$ It may even be that the presence of a species able to provide at least three hydrogen bonds, as 
observed here, is important, as $\mathrm{PPh}_{4}{ }^{+}$and $\mathrm{H}_{2} \mathrm{NMe}_{2}{ }^{+}$together with uranyl ion and trans-1,2-cyclohexanedicarboxylate provide only what can be regarded as a precursor to a cage species. ${ }^{60}$

Of the many factors which determine the nature of a metal ion coordination complex, "flexibility" of the ligand is an important but multi-faceted influence. ${ }^{32-34}$ Bridging by a ligand can result in the formation of coordination polymers as well as the formation of closed oligonuclear species, notably in the case of the uranyl ion, ${ }^{4}$ and the latter have long attracted interest as the possible source of cavities suited to selective guest inclusion and reactions. Uranyl ion provides a relatively novel species upon which formation of cavitycontaining clusters might be based and indeed rather few examples involving carboxylate ligands are presently known. ${ }^{4,35}$

In polycarboxylates such as that used here, it is possible for the carboxylate units to display different bonding modes, and thus it is unsurprising to find that the structural chemistry of uranyl polycarboxylates shows great variability. ${ }^{1-4}$ One means of limiting this variability is to attach the carboxylate units to scaffolds with little or no conformational freedom, thus enabling effects associated with just the bonding modes and rotational freedom of the carboxylate units to be identified with some certainty. To this end, we have explored the complexation by uranyl ion of a number of polycarboxylate derivatives of cyclohexane ${ }^{12,13,28,35,58}$ and adamantane. ${ }^{36,37,46}$ The case of 1,3 -adamantanedicarboxylate $\left(\mathrm{ADC}^{2-}\right)^{37,46}$ is interesting in that the particularly rigid scaffold limits any rotational freedom to that of the $\mathrm{C}-\mathrm{CO}_{2}{ }^{-}$bonds and ensures that regardless of their rotameric form the ligand must still be regarded as bent and potentially able to form closed species. On the basis of the known structures of uranyl ion complexes of this ligand, it appears that the protons of the methylene group linking the two carboxylate-substituted centres have little influence on rotation about the $\mathrm{C}-\mathrm{CO}_{2}^{-}$bonds, since the nearest $\mathrm{C}-\mathrm{O}$ bonds adopt orientations which in some cases are essentially parallel to the axial and in others to the equatorial $\mathrm{C}-\mathrm{H}$ bond, while in yet others there is no projection of one vector on the other. They may, however, inhibit any approach of one or two uranyl ions to two oxygen atoms of separate carboxylate groups in conformations where these donors are as close as possible, as it is observed that the ligand does not function as a simple chelate of a single uranium, nor does it form a bridge using the closer oxygen atoms. A common feature is the presence of fused metallacyclic units where a relatively small 8-membered ring is formed by two carboxylate groups of separate ligands bridging uranyl centres in a $\mu_{2}-\kappa^{1} O: \kappa^{1} O^{\prime}$ manner and a larger 16-membered ring is formed by unsymmetrical bridging by ligand units where one carboxylate chelates uranium $\left(\kappa^{2} O, O^{\prime}\right)$ and the other binds through a single oxygen. The smaller ring is close to planar in all cases but the larger shows a variable degree of buckling consistent with an approach to the formation of a cavity-containing structure (Figure S4). Despite some variety, it is clear that $\mathrm{ADC}^{2-}$ functions exclusively as a bridging ligand and that while it could be considered as a bent donor capable of forming closed coordination structures, such as have been observed in uranyl ion complexes of 1,2-cyclohexanedicarboxylates, for example, ${ }^{12,13,35}$ there is no apparent tendency for it to do so.

An incremental change in ligand flexibility, essentially free rotation about a new $\mathrm{C}-\mathrm{C}$ bond, is associated with progress from $\mathrm{ADC}^{2-}$ to $\mathrm{ADA}^{2-}$. Its consequences are readily seen when the ligand donor atom arrays seen in the former (Figure S5) are compared with those in known uranyl ion complexes of the latter, including the present ones (Figure S6). There are cases of close similarity and both can provide donor atom arrays suited to the formation of monocyclic entities (Figure S7), with some of the lattices containing ribbon structures involving the linking of 8 - and 16membered uranyl-containing rings. ${ }^{36}$ In $\left[\mathrm{UO}_{2}(\mathrm{ADA})\right] \cdot 0.5 \mathrm{CH}_{3} \mathrm{CN}$, however, $\mathrm{ADA}^{2-}$ plays a role as an essentially linear linker, with bonding interactions unlike any observed with $\mathrm{ADC}^{2-}$, and this tendency is reflected in the 2-dimensional sheets found in [ $\left.\mathrm{UO}_{2}(\mathrm{ADA})(\mathrm{DMF})\right]$ where 8-membered dimetallacycles are linked to 40membered tetrametallacyclic units, the form of the latter indicating that the preferred effective curvature of $\mathrm{ADA}^{2-}$ is less than that of $\mathrm{ADC}^{2-}$. A similar 40-membered ring can be identified within the thick layers found in the lattice of $\left[\mathrm{H}_{2} \mathrm{NMe}_{2}\right]\left[\left(\mathrm{UO}_{2}\right)_{2}(\mathrm{ADA})_{3}\right] \cdot 3 \mathrm{H}_{2} \mathrm{O}$, however, and here, seemingly as a result of hydrogen bonding interactions involving the additional $\mathrm{H}_{2} \mathrm{NMe}_{2}{ }^{+}$cations, there is progession towards a $3 \mathrm{D}$, cavity-containing array. This effect of a second cation is of interest not only because it appears to be related to hydrogen bonding interactions but also because it occurs with a cation which, unlike many metal cations, does not quench luminescence of uranyl ion, a favourable occurrence in relation to the objective of obtaining uranyl coordination cages of potential use as photocatalysts.

Luminescence Properties. Emission spectra under excitation at a wavelength of $420 \mathrm{~nm}$ were recorded in the solid state for all compounds 1-3 (Figure 7). The intense and well-resolved spectra are nearly superimposable, and they display the usual vibronic fine structure corresponding to the $S_{11} \rightarrow S_{00}$ and $S_{10} \rightarrow S_{0 v}$ ( $v=0-4)$ electronic transitions. ${ }^{61}$ The five main peaks are centered at $465,482,502,524$, and $547 \mathrm{~nm}$, these values being typical of compounds containing uranyl cations chelated by three carboxylate groups ${ }^{58}$ (the peaks for complexes with five equatorial donors being red-shifted). Solid state photoluminescence quantum yields (PLQYs) of 0.06, 0.06, and 0.09 (with a standard deviation of $c a \pm 2.5 \%$ ) were measured for compounds $\mathbf{1}, \mathbf{2}$ and $\mathbf{3}$, respectively, these values being comparable to those of 0.06 and 0.13 measured in a uranyl octanuclear cage complex with cis-1,2cyclohexanedicarboxylate $^{35}$ and a two-dimensional assembly with trans-1,4-cyclohexanedicarboxylate, ${ }^{60}$ respectively. The two discrete complexes $\mathbf{1}$ and $\mathbf{2}$, only differing by a small change in the counter cation, feature, as expected, the same PLQY. The PLQYs for the polymeric species appear to be slightly larger than those for discrete clusters, which may be due to the longer $\mathrm{U} \cdots \mathrm{U}$ distances in the former, the shortest distances being 6.1851(3) $\AA$ in $\mathbf{1}, 6.7346(4) \AA$ in $\mathbf{2}$, 
7.6138(3) $\AA$ in $3,5.3669(6) \AA$ in the previous octanuclear cage, ${ }^{35}$ and 7.8239(4) $\AA$ in the previous 2D network. ${ }^{60}$ However, additional measurements on more extended and diverse series of compounds are obviously needed before any definite conclusion can be drawn.

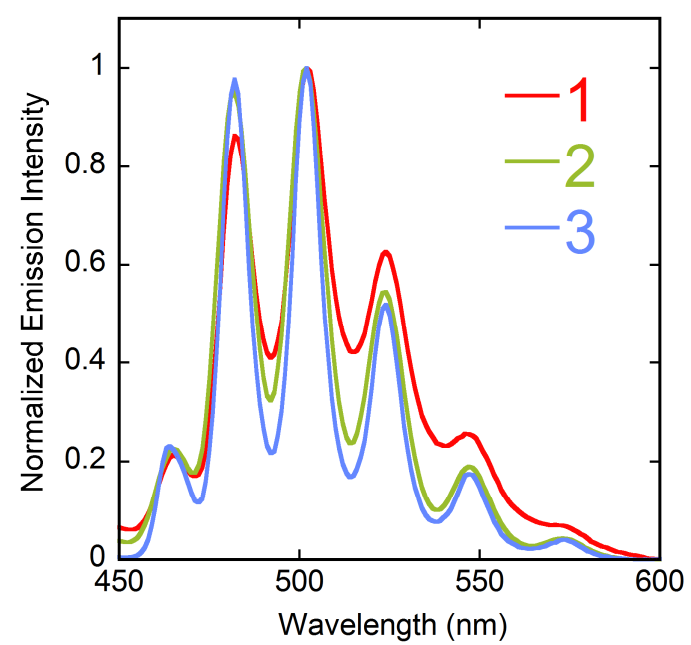

Figure 7. Solid state emission spectra of complexes 1-3 under excitation at $420 \mathrm{~nm}$.

\section{CONCLUSIONS}

The metallatricycle species $\mathbf{1}$ and $\mathbf{2}$ described herein add to the family of coordination cages incorporating uranyl ion and although they are like some others in that half the uranyl oxo groups, potentially sites for hydrogen bonding to guests, are directed towards the interior of the cage, here they form two groups rather than being directed to a single central point. These essentially identical metallatricycles are therefore best described as a ditopic cage with binding sites separated by just over $9 \AA$ and suited perhaps to the binding of diammonium guests. There appears to be a role for multiple hydrogen bonding in inducing a flexible ligand to adopt a conformation suited to the formation of closed structures but this can be only part of the story in relation to the metallatricycle characterized in the present work, as two ligand units within this tricycle adopt a conformation with divergent orientation of the carboxylate donors, and interactions with the large phosphonium cations must be a factor favouring the formation of a closed species rather than a polymer. The phosphonium cations in the lattices of both complexes $\mathbf{1}$ and $\mathbf{2}$ block access to the cage cavity and it remains to be established whether a solvent in which the complex is soluble can be found and whether the cage form would be retained in solution, without blockage of the two clefts by the $\mathrm{PPh}_{4}{ }^{+}$or $\mathrm{PPh}_{3} \mathrm{Me}^{+}$cations, so as to possibly enabling other guests to enter.

\section{ASSOCIATED CONTENT}

\section{Accession Codes}

CCDC 1837482-1837484 contain the supplementary crystallographic data for this paper. These data can be obtained free of charge via www.ccdc.cam.ac.uk/data_request/cif, or by emailing data_request@ccdc.cam.ac.uk, or by contacting The Cambridge Crystallographic Data Centre, 12 Union Road, Cambridge CB2 1EZ, UK; fax: +44 1223336033.

\section{Supporting Information}

Figures S1-S7. This information is available free of charge via the Internet at http://pubs.acs.org/.

\section{AUTHOR INFORMATION}

\section{Corresponding Author}

*E-mail for P.T.: pierre.thuery@cea.fr

*E-mail for J.H.: harrowfield@unistra.fr

\section{ORCID}

Pierre Thuéry: 0000-0003-1683-570X

Youssef Atoini: 0000-0003-4851-3713

Jack Harrowfield: 0000-0003-4005-740X

Notes

The authors declare no competing financial interest.

\section{REFERENCES}

1. Andrews, M. B.; Cahill, C. L. Uranyl Bearing Hybrid Materials: Synthesis, Speciation, and Solid-State Structures. Chem. Rev. 2013, 113, 1121-1136.

2. Loiseau, T.; Mihalcea, I.; Henry, N.; Volkringer, C. The Crystal Chemistry of Uranium Carboxylates. Coord. Chem. Rev. 2014, 266267, 69-109.

3. Su, J.; Chen, J. S. MOFs of Uranium and the Actinides. Struct. Bond. 2015, 163, 265-296.

4. Thuéry, P.; Harrowfield, J. Recent Advances in Structural Studies of Heterometallic Uranyl-Containing Coordination Polymers and Polynuclear Closed Species. Dalton Trans. 2017, 46, 13660-13667.

5. Thuéry, P.; Villiers, C.; Jaud, J.; Ephritikhine, M.; Masci, B. UranylBased Metallamacrocycles: Tri- and Tetranuclear Complexes with $(2 R, 3 R, 4 S, 5 S)$-Tetrahydrofurantetracarboxylic Acid. J. Am. Chem. Soc. 2004, 126, 6838-6839.

6. Charushnikova, I. A.; Grigor'ev, M. S.; Krot, N. N. Synthesis and Crystal Structure of New U(VI) and Np(VI) Benzoates, $\mathrm{K}_{11}\left(\mathrm{AnO}_{2}\right)_{23}\left(\mathrm{OOCC}_{6} \mathrm{H}_{5}\right)_{57}\left(\mathrm{H}_{2} \mathrm{O}\right)_{18+x}$. Radiochemistry 2010, 52, 138144.

7. Thuéry, P. Increasing Complexity in the Uranyl Ion-Kemp's Triacid System: From One- and Two-Dimensional Polymers to Uranyl-Copper(II) Dodeca- and Hexadecanuclear Species. Cryst. Growth Des. 2014, 14, 2665-2676.

8. Thuéry, P.; Nierlich, M.; Baldwin, B. W.; Komatsuzaki, N.; Hirose, T. A Metal-Organic Molecular Box Obtained from Self-Assembling around Uranyl Ions. J. Chem. Soc., Dalton Trans., 1999, 1047-1048.

9. Thuéry, P. A Nanosized Uranyl Camphorate Cage and its Use as a Building Unit in a Metal-Organic Framework. Cryst. Growth Des. 2009, 9, 4592-4594.

10. Thuéry, P. A Highly Adjustable Coordination System: Nanotubular and Molecular Cage Species in Uranyl Ion Complexes with Kemp's Triacid. Cryst. Growth Des. 2014, 14, 901-904.

11. Thuéry, P.; Harrowfield, J. A New Form of Triple-Stranded Helicate Found in Uranyl Complexes of Aliphatic $\alpha, \omega$-Dicarboxylates. Inorg. Chem. 2015, 54, 10539-10541.

12. Thuéry, P.; Harrowfield, J. Coordination Polymers and CageContaining Frameworks in Uranyl Ion Complexes with rac- and $(1 R, 2 R)$-trans-1,2-Cyclohexanedicarboxylates: Consequences of Chirality. Inorg. Chem. 2017, 56, 1455-1469.

13. Thuéry, P.; Harrowfield, J. Tetrahedral and Cuboidal Clusters in Complexes of Uranyl and Alkali or Alkaline-Earth Metal Ions with rac- and $(1 R, 2 R)$-trans-1,2-Cyclohexanedicarboxylate. Cryst. Growth Des. 2017, 17, 2881-2892. 
14. Pasquale, S.; Sattin, S.; Escudero-Adán, E. C.; Martínez-Belmonte, M.; de Mendoza, J. Giant Regular Polyhedra from Calixarene Carboxylates and Uranyl. Nature Commun. 2012, 3, 785-791.

15. Qiu, J.; Burns, P. C. Clusters of Actinides with Oxide, Peroxide, or Hydroxide Bridges. Chem. Rev. 2013, 113, 1097-1120.

16. Ling, J.; Hobbs, F.; Prendergast, S.; Adelani, P. O.; Babo, J. M.; Qiu, J.; Weng, Z.; Burns, P. C. Hybrid Uranium-Transition-Metal Oxide Cage Clusters. Inorg. Chem. 2014, 53, 12877-12884.

17. Sigmon, G. E.; Szymanowski, J. E. S.; Carter, K. P.; Cahill, C. L.; Burns, P. C. Hybrid Lanthanide-Actinide Peroxide Cage Clusters. Inorg. Chem. 2016, 55, 2682-2684.

18. Dembowski, M.; Olds, T. A.; Pellegrini, K. L.; Hoffmann, C.; Wang, X.; Hickam, S.; He, J.; Oliver, A. G.; Burns, P. C. Solution ${ }^{31}$ P NMR Study of the Acid-Catalyzed Formation of a Highly Charged $\left\{\mathrm{U}_{24} \mathrm{Pp}_{12}\right\}$ Nanocluster, $\quad\left[\left(\mathrm{UO}_{2}\right)_{24}\left(\mathrm{O}_{2}\right)_{24}\left(\mathrm{P}_{2} \mathrm{O}_{7}\right)_{12}\right]^{48-}$, and Its Structural Characterization in the Solid State Using Single-Crystal Neutron Diffraction. J. Am. Chem. Soc. 2016, 138, 8547-8553.

19. Hickam, S.; Burns, P. C. Oxo Clusters of $5 f$ Elements. Struct. Bonding (Berlin, Ger.) 2017, 173, 121-154.

20. Poojary, D. M.; Cabeza, A.; Aranda, M. A. G.; Bruque, S.; Clearfield, A. Structure Determination of a Complex Tubular Uranyl Phenylphosphonate, $\left(\mathrm{UO}_{2}\right)_{3}\left(\mathrm{HO}_{3} \mathrm{PC}_{6} \mathrm{H}_{5}\right)_{2}\left(\mathrm{O}_{3} \mathrm{PC}_{6} \mathrm{H}_{5}\right)_{2} \cdot \mathrm{H}_{2} \mathrm{O}$, from Conventional X-ray Powder Diffraction Data. Inorg. Chem. 1996, 35, 1468-1473.

21. Grohol, D.; Clearfield, A. Alkali-Ion-Catalyzed Transformation of Two Linear Uranyl Phosphonates into a Tubular One. J. Am. Chem. Soc. 1997, 119, 9301-9302.

22. Krivovichev, S. V.; Kahlenberg, V.; Tananaev, I. G.; Kaindl, R.; Mersdorf, E.; Myasoedov, B. F. Highly Porous Uranyl Selenate Nanotubules. J. Am. Chem. Soc. 2005, 127, 1072-1073.

23. Krivovichev, S. V.; Kahlenberg, V.; Kaindl, R.; Mersdorf, E.; Tananaev, I. G.; Myasoedov, B. F. Nanoscale Tubules in Uranyl Selenates. J. Angew. Chem. Int. Ed. 2005, 44, 1134-1136.

24. Mihalcea, I.; Henry, N.; Loiseau T. Revisiting the Uranyl-Phthalate System: Isolation and Crystal Structures of Two Types of UranylOrganic Frameworks (UOF). Cryst. Growth Des. 2011, 11, 1940-1947.

25. Adelani, P. O.; Albrecht-Schmitt, T. E. Metal-Controlled Assembly of Uranyl Diphosphonates toward the Design of Functional Uranyl Nanotubules. Inorg. Chem. 2011, 50, 12184-12191.

26. Unruh, D. K.; Gojdas, K.; Libo, A.; Forbes, T. Z. Development of Metal-Organic Nanotubes Exhibiting Low-Temperature, Reversible Exchange of Confined "Ice Channels". J. Am. Chem. Soc. 2013, 135, 7398-7401.

27. Adelani, P. O.; Cook, N. D.; Babo, J. M.; Burns, P. C. Incorporation of $\mathrm{Cu}^{2+}$ Ions into Nanotubular Uranyl Diphosphonates. Inorg. Chem. 2014, 53, 4169-4176.

28. Thuéry, P.; Harrowfield, J. Uranyl Ion Complexes with all-cis-1,3,5Cyclohexanetricarboxylate: Unexpected Framework and Nanotubular Assemblies. Cryst. Growth Des. 2014, 14, 4214-4225.

29. Jayasinghe, A. S.; Unruh, D. K.; Kral, A.; Libo, A.; Forbes, T. Z. Structural Features in Metal-Organic Nanotube Crystals That Influence Stability and Solvent Uptake. Cryst. Growth Des. 2015, 15, 4062-4070.

30. Thuéry, P.; Harrowfield, J. Variations on the Honeycomb Topology: from Triangular- and Square-Grooved Networks to Tubular Assemblies in Uranyl Tricarballylate Complexes. Cryst. Growth Des. 2017, 17, 963-966.

31. Caulder, D. L; Raymond, K. N. Supermolecules by Design. Acc. Chem. Res. 1999, 32, 975-982.

32. Comba, P.; Schiek, W. Fit and Misfit between Ligands and Metal Ions. Coord. Chem. Rev. 2003, 238-239, 21-29.

33. Steel, P. J. Ligand Design in Multimetallic Architectures: Six Lessons Learned. Acc. Chem. Res. 2005, 38, 243-250.

34. Lin, Z. J.; Lü, J.; Hong, M.; Cao, R. Metal-Organic Frameworks based on Flexible Ligands (FL-MOFs): Structures and Applications. Chem. Soc. Rev. 2014, 43, 5867-5895.

35. Thuéry, P.; Atoini, Y.; Harrowfield, J. Counterion-Controlled Formation of an Octanuclear Uranyl Cage with cis-1,2Cyclohexanedicarboxylate Ligands. Inorg. Chem., DOI: 10.1021/acs.inorgchem.8b00147.

36. Thuéry, P.; Harrowfield, J. Solvent Effects in Solvo-Hydrothermal Synthesis of Uranyl Ion Complexes with 1,3-Adamantanediacetate. CrystEngComm 2015, 17, 4006-4018.

37. Thuéry, P. Uranyl Complexes as Scaffolding or Spacers for Cucurbit[6]uril Molecules in Homo- and Heterometallic Species,
Including a Uranyl-Lanthanide Complex. Eur. J. Inorg. Chem. 2017, 2876-2882.

38. Hooft, R. W. W. COLLECT, Nonius BV: Delft, The Netherlands, 1998.

39. Otwinowski, Z.; Minor, W. Processing of X-Ray Diffraction Data Collected in Oscillation Mode. Methods Enzymol. 1997, 276, 307-326.

40. Sheldrick, G. M. SHELXT - Integrated Space-Group and CrystalStructure Determination. Acta Crystallogr., Sect. A 2015, 71, 3-8.

41. Sheldrick, G. M. Crystal Structure Refinement with SHELXL. Acta Crystallogr., Sect. C 2015, 71, 3-8.

42. Spek, A. L. PLATON SQUEEZE: a Tool for the Calculation of the Disordered Solvent Contribution to the Calculated Structure Factors. Acta Crystallogr., Sect. C 2015, 71, 9-18.

43. Farrugia, L. J. WinGX and ORTEP for Windows: an Update. J. Appl. Crystallogr. 2012, 45, 849-854.

44. Momma, K.; Izumi, F. VESTA: a Three-Dimensional Visualization System for Electronic and Structural Analysis. J. Appl. Crystallogr. 2008, 41, 653-658.

45. Rusanova, J. A.; Rusanov, E. B.; Domasevitch, K. V. A New Adamantanecarboxylate Coordination Polymer: Poly[[ $\left(\mu_{3}-\right.$ Adamantane-1,3-dicarboxylato)aquadioxidouranium(VI)] monohydate]. Acta Cryst., Sect. C 2010, 66, m207-m210.

46. Thuéry, P.; Rivière, E.; Harrowfield, J. Uranyl and Uranyl-3d Block Cation Complexes with 1,3-Adamantanedicarboxylate: Crystal Structures, Luminescence and Magnetic Properties. Inorg. Chem. 2015, 54, 2838-2850.

47. Groom, C. R.; Bruno, I. J.; Lightfoot, M. P.; Ward, S. C. The Cambridge Structural Database. Acta Crystallogr., Sect. B 2016, 72, $171-179$.

48. Zhang, W. H.; Wang, Y. Y.; Lermontova, E. K.; Yang, G. P.; Liu, B.; Jin, J. C.; Dong, Z.; Shi, Q. Z. Interaction of 1,3-Adamantanediacetic Acid $\left(\mathrm{H}_{2} \mathrm{ADA}\right)$ and Ditopic Pyridyl Subunits with Cobalt Nitrate under Hydrothermal Conditions: $\mathrm{pH}$ Influence, Crystal Structures, and Their Properties. Cryst. Growth Des. 2010, 10, 76-84.

49. Zhang, W. H.; Dong, Z.; Wang, Y. Y.; Hou, L.; Jin, J. C.; Huang, W. H.; Shi, Q. Z. Synthesis, Structural Diversity and Fluorescent Characterisation of a Series of $\mathrm{d}^{10}$ Metal-Organic Frameworks (MOFs): Reaction Conditions, Secondary Ligand and Metal Effects. Dalton Trans. 2011, 40, 2509-2521.

50. Ren, C.; Zhang, Y. N.; Shi, W. J.; Liu, B.; Wang, Y. Y.; Shi, Q. Z. Structural Diversity of Coordination Polymers Assembled from Adamantane Dicarboxylates and Conformational bis-Triazole Ligand. CrystEngComm, 2011, 13, 5179-5189.

51. Fikes, A. G.; Gwini, N.; Yoon, S. H.; Nesterov, V. N.; Powell, G. L. Di- and Tetraosmium Carbonyl Complexes with Dicarboxylato Ligands Serving as Intramolecular Rings and Intermolecular Bridges. J. Organomet. Chem. 2014, 772-773, 188-191.

52. Taylor, R.; Kennard, O. Crystallographic Evidence for the Existence of $\mathrm{C}-\mathrm{H} \cdots \mathrm{O}, \mathrm{C}-\mathrm{H} \cdots \mathrm{N}$, and $\mathrm{C}-\mathrm{H} \cdots \mathrm{Cl}$ Hydrogen Bonds. J. Am. Chem. Soc. 1982, 104, 5063-5070.

53. Desiraju, G. R. The C-H ‥ O Hydrogen Bond: Structural Implications and Supramolecular Design. Acc. Chem. Res. 1996, 29, 441-449.

54. Taylor, R. It Isn't, It Is: The C-H $\cdots X(X=\mathrm{X}, \mathrm{N}, \mathrm{F}, \mathrm{Cl})$ Interaction Really Is Significant in Crystal Packing. Cryst. Growth Des. 2016, 16, 4165-4168.

55. Spackman, M. A.; Jayatilaka, D. Hirshfeld Surface Analysis. CrystEngComm 2009, 11, 19-32.

56. Wolff, S. K.; Grimwood, D. J.; McKinnon, J. J.; Turner, M. J.; Jayatilaka, D.; Spackman, M. A. CrystalExplorer, University of Western Australia, 2012.

57. Scudder, M.; Dance, I. Crystal Supramolecular Motifs. Two- and Three-Dimensional Networks of $\mathrm{Ph}_{4} \mathrm{P}^{+}$Cations Engaged in Sixfold Phenyl Embraces. J. Chem. Soc., Dalton Trans 1998, 3167-3175, and references therein.

58. Thuéry, P.; Harrowfield, J. Structural Consequences of 1,4Cyclohexanedicarboxylate cis/trans Isomerism in Uranyl Ion Complexes: from Molecular Species to 2D and 3D Entangled Nets. Inorg. Chem. 2017, 56, 13464-13481.

59. Thuéry, P.; Harrowfield, J. Modulation of the Structure and Properties of Uranyl Ion Coordination Polymers Derived from 1,3,5Benzenetriacetate by Incorporation of $\mathrm{Ag}(\mathrm{I})$ or $\mathrm{Pb}(\mathrm{II})$. Inorg. Chem. 2016, 55, 6799-6816 and references therein.

60. Thuéry, P.; Atoini, Y.; Harrowfield, J. Uranyl-Organic Coordination Polymers with trans-1,2-, trans-1,4- and cis-1,4Cyclohexanedicarboxylates: Effects of Bulky $\mathrm{PPh}_{4}{ }^{+}$and $\mathrm{PPh}_{3} \mathrm{Me}^{+}$ Counterions. Cryst. Growth Des. 2018, 18, 2609-2619.

61. Brachmann, A.; Geipel, G.; Bernhard, G.; Nitsche, H. Study of Uranyl(VI) Malonate Complexation by Time Resolved Laser-Induced Fluorescence Spectroscopy (TRLFS). Radiochim. Acta 2002, 90, 147153. 


\section{Closed Uranyl-Dicarboxylate Oligomers: a Tetranuclear Metallatricycle with Uranyl Bridgeheads and 1,3- Adamantanediacetate Linkers}

Pierre Thuéry, Youssef Atoini and Jack Harrowfield

In the presence of ammonium and either $\mathrm{PPh}_{4}{ }^{+}$or $\mathrm{PPh}_{3} \mathrm{Me}^{+}$cations, 1,3-adamantanediacetate reacts with uranyl ions to form a tetranuclear metallatricycle built from two 2:2 rings linked by two additional ligands. While the ammonium cations are closely associated to the 2:2 rings through hydrogen bonding, the large $\mathrm{PPh}_{4}^{+}$or $\mathrm{PPh}_{3} \mathrm{Me}^{+}$cations are more loosely bound to each of the two clefts defined by the metal complex.

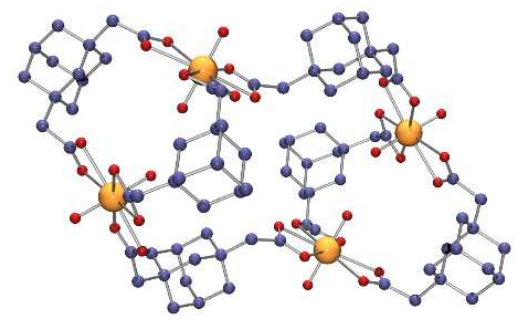

